\title{
Educação Ambiental e Movimentos Sociais: reflexões e questões levantadas no GDP
}

\author{
Carlos Frederico B. Loureiro ${ }^{1}$ \\ UFRJ - Faculdade de Educação
}

resumo: $\mathrm{O}$ amplo universo de temas e questões identificados e explicitados no GDP "Pesquisa em Educação Ambiental e Movimentos Sociais", ao se problematizar a relação entre educação ambiental e movimentos sociais, evidencia o quanto essa discussão é relevante e precisa ser considerada por aqueles que realizam pesquisas acadêmicas em educação ambiental. No presente artigo, sistematizamos as reflexões do grupo e sugestões de encaminhamento levantadas, tendo por finalidade contribuir com: a identificação das principais questões de pesquisa, o diálogo entre educadores e educadoras ambientais e militantes de movimentos sociais e a promoção de estudos que enfocam e reconhecem a importância de tal relação no contexto histórico e sociopolítico contemporâneo.

palavras-chave: Movimentos Sociais, Práxis, Pesquisa em Educação Ambiental.

abstract: The wide universe of subjects and questions identified and shown at the "Research in Environmental Education and Social Movements" RDG (Research and Discussion Group), when the relation between Environmental Education and Social Movements was discussed, makes clear the relevance of this discussion and how much it needs to be taken into account by those who do academic researches in Environmental Education. In the present article, we systematized the thoughts and the leading suggestions raised by the group, aiming to help: identifying the main research questions; the dialog between environmental educators and militants of social movements; and the promotion of studies that recognize the importance of such a relation in contemporary sociopolitical and historical context.

keywords: Social Movements, Praxis, Research in Environmental Education.

\section{Introdução}

Durante a realização do Grupo de Discussão e Pesquisa "Pesquisa em Educação Ambiental e Movimentos Sociais" no IV Encontro de

\footnotetext{
${ }_{1}^{1}$ E-mail: floureiro@openlink.com.br
} 
Pesquisa em Educação Ambiental (EPEA), ocorrido em julho de 2007, alguns fatos e falas evidenciaram aspectos que merecem destaque e que demonstram a pertinência deste GDP. A presença do público foi excepcional, considerando a natureza da atividade, com média de participação em torno de setenta pessoas. O interesse em dialogar sobre o tema e buscar esclarecimentos sobre conceitos e possibilidades metodológicas para as pesquisas e acerca de aspectos práticos relativos à presença de educadores e educadoras ambientais em movimentos sociais foi igualmente destacado. Questões como: o que são movimentos sociais? O que diferencia sociedade civil de terceiro setor? Qual a importância dos movimentos sociais para a democratização do Estado brasileiro e para a construção de sociedades sustentáveis? O que diferencia um movimento social das formas de atuação majoritariamente observadas entre as ONGs? Como formar ambientalmente os militantes de movimentos sociais? É possível considerar que um movimentos social, por sua prática, já tem implícita a discussão ambiental?, entre outras, permearam o conjunto das exposições e evidenciam a diversidade e complexidade de indagações que este GDP pode trazer para os debates em educação ambiental.

Todavia, antes de entrar nas considerações teóricas feitas e nas questões de pesquisa que surgiram ou foram ratificadas a partir do textobase, o grupo definiu, ao final, duas sugestões encaminhadas à organização do evento no momento de relato do GDP e que consideramos pertinente apresentar neste item introdutório:

- que este GDP seja permanente, garantindo a continuidade dos trabalhos no próximo encontro. Isso, se confirmado, implica a definição, pelos organizadores, da sistemática de funcionamento, inclusive mandato da coordenação e atribuições.

- que no próximo EPEA a discussão sobre educação ambiental e movimentos sociais tenha um espaço maior na programação. Isso significa sua inclusão como tema de mesa redonda e/ou conferência e/ou como objeto de minicurso específico que ajude na construção e entendimento de conceitos pouco conhecidos na educação ambiental (por mais que sejam mencionados). É consensual para o grupo presente à atividade que esses conceitos precisam ser apreendidos para que ocorra uma práxis política e educativa conscientemente compatível com as diretrizes da própria Política 
Nacional de Educação Ambiental ou que a esta se faça legítimo e democrático enfrentamento. São possibilidades de ações não excludentes entre si na programação do evento e que não se confundem com o trabalho do GDP, focado na produção científica e em questões de pesquisa decorrentes da relação que é seu objeto de estudo.

A seguir, apresentamos os pontos abordados, mesclando alguns detalhamentos conceituais, necessários diante das perguntas feitas, e questões de pesquisa equivalentes.

\section{Principais questões e reflexões}

As discussões sobre o sentido educativo dos movimentos sociais e os processos de formação dos sujeitos que destes participam não são novas no campo da educação. Para ilustrar, basta lembrar o já consolidado GT03 - Movimentos Sociais e Educação, da Associação Nacional de PósGraduação e Pesquisa em Educação (Anped) e a vasta literatura produzida abordando o princípio educativo dos movimentos sociais (CALDART, 1997, 2005; GOHN, 2002). Contudo, apesar de sua relevância, a temática ainda é muito pouco trabalhada na educação ambiental (EA) enquanto objeto de pesquisa. Poucos foram os momentos em sua história no Brasil em que a presença de integrantes de movimentos sociais se fez com destaque em situações importantes como conferências dos principais eventos nacionais e internacionais ocorridos ou em espaços públicos de deliberação. E mais: poucos são os trabalhos sistematizados sobre o tema que alcançaram espaços significativos não só em eventos, mas em periódicos reconhecidos pelo meio acadêmico e científico.

Tal constatação já gera uma primeira demanda específica ao GDP, enquanto questão de pesquisa: realizar com maior precisão o "estado da arte" relativo ao tratamento e presença dos movimentos sociais no âmbito da educação ambiental, para além dessas impressões gerais compartilhadas pelo grupo.

Diante dessa primeira lacuna identificada, cabe discorrer, mesmo que sinteticamente, sobre as seguintes colocações (aqui não identificadas como questões de pesquisa propriamente ditas, mas como problemas postos que ajudam na explicitação de premissas teóricas que permitem 
estabelecer a relação entre educação ambiental e movimentos sociais): quais são os motivos que geraram historicamente a preocupação em relacionar movimentos sociais e educação? Afinal, qual é o sentido educativo inerente à prática dos movimentos sociais?

Quando se entende que a educação se refere aos múltiplos processos sociais pelos quais nos constituímos como humanos, particularmente à sua condição de ser social (NETTO; BRAZ, 2007), e a partir dos quais diferentes saberes são criados e recriados sob condições específicas, gerando cultura, a questão começa a ser compreendida (LOUREIRO, 2006a). Esse tipo de posicionamento se pauta no pressuposto de que, se os indivíduos se definem enquanto tal por meio das relações sociais, educar é uma prática social dialógica intencional que está para além da sensibilização ou da acumulação de conhecimentos (componentes necessários ao processo, mas não suficientes), encontrandose também na consciência acerca da realidade ao agirmos nesta pela práxis (SAVIANI, 2003).

Com efeito, se cada indivíduo humano sintetiza relações sociais, isto significa que ele só se constitui como homem por meio das relações que estabelece com os outros homens, isto é, só pode tornar-se homem se incorporar em sua própria subjetividade formas de comportamento e idéias criadas pelas gerações anteriores e retrabalhadas por ele e por aqueles que com ele convivem (SAVIANI, 2004, p. 46).

E qual é a intencionalidade pressuposta na atividade educativa quando pensamos em movimentos sociais? Ora, se a condição humana se define na totalidade das relações estabelecidas historicamente, a sua emancipação (pela superação das relações de dominação e expropriação inerentes a determinada formação social) encontra-se vinculada ao "estar" e agir no mundo (LOUREIRO, 2007). É por isso que Paulo Freire nos ensina:

O que nos parece indiscutível é que, se pretendemos a libertação dos homens, não podemos começar por aliená-los ou mantê-los alienados. A libertação autêntica, que é a humanização em processo, não é uma coisa que se deposita nos homens. Não é uma palavra a mais, oca, mitificante. É práxis, que implica a ação e a reflexão dos homens sobre o mundo para transformá-lo (FREIRE, 1988, p.67). 
E igualmente Tertulian (2004, p.7) destaca: "se a essência do homem se define com a totalidade das relações sociais, então a realização e a libertação do gênero humano estão indissociavelmente ligadas à transformação do mundo".

É, conseqüentemente, por meio do conhecimento das especificidades sociais em suas interfaces desenhadas na história (classes, grupos sociais, etnia, gênero, família, comunidade, região, Estado, relações de apropriação e produção etc.) que se torna possível entender, na práxis educativa, o sentido de adequação ou não das relações sociais na natureza, atuando para reproduzi-las ou modificá-las (TOZONI-REIS, 2004).

No caso específico da educação ambiental, que admite esses aspectos, pelo menos para algumas de suas abordagens, ao se afirmar o seu caráter político e transformador no Tratado de Educaşão Ambiental para Sociedades Sustentáveis e Responsabilidade Global, na PNEA e no ProNEA, há um outro componente a ser destacado. Não é nova a crítica às ações descontextualizadas que querem promover a proteção da natureza e uma ética ecológica sem considerar a concretude da realidade em que se está imerso, particularmente dos agentes do processo educativo com os quais se dialoga e trabalha na construção da "comunidade de aprendizagem" (LOUREIRO, 2004). Prática que acarreta desde problemas de inadequação pedagógica até o tratamento de conteúdos que pouco se relacionam com a dinâmica social em que se estabelece a discussão ambiental, inviabilizando a necessária autonomia dos sujeitos na construção de padrões societários sustentáveis.

Com isso, ao se pensar a educação ambiental, considerando os movimentos sociais e as implicações políticas destes, se agregam ao processo instaurado: os conflitos socioambientais, os problemas decorrentes dos usos e apropriações da natureza, os interesses e necessidades em disputa, as visões societárias antagônicas, a configuração política e institucional, as mobilizações sociais; enfim, os agentes sociais concretos em suas relações constitutivas na dinâmica contraditória da sociedade (ACSELRAD, 2004; ACSELRAD; HERCULANO; PÁDUA, 2004; QUINTAS, 2000). O que é um inegável ganho qualitativo para a educação ambiental no atendimento de suas diretrizes e objetivos, pelo menos tal como estão definidas no escopo legal e normativo brasileiro. 
Feito esse esclarecimento conceitual, partindo do pressuposto de que há concordância entre os educadores e educadoras ambientais que atuam junto a movimentos sociais de que estes possuem intrinsecamente um sentido educativo, emergem outras três questões de pesquisa: como os movimentos sociais promovem a educação, particularmente a educação ambiental? Esta aparece em suas finalidades? Quais são os movimentos sociais mais permeáveis ao tratamento da educação ambiental, em particular, e da questão ambiental, em geral?

Decorre também desse primeiro conjunto de reflexões a seguinte questão: os movimentos sociais se caracterizam, de fato, como sujeitos relevantes de pesquisa, diálogo e atuação conjunta com educadores e educadoras ambientais em todas as suas abordagens?

Parece evidente que para as abordagens classificadas como críticas, transformadoras e emancipatórias (LAYRARGUES, 2004; LIMA, 2002), os movimentos sociais são sujeitos protagonistas do processo educativo ambiental. Todavia, é difícil afirmar, sem estudos mais detalhados, como outras abordagens tidas como conservacionistas, comportamentalistas ou que trabalham estritamente com as relações ecológicas enxergam os movimentos sociais e os entendem ou não como sujeitos do processo educativo. $\mathrm{O}$ dado de realidade é que nem sempre a relação entre a educação ambiental e os movimentos sociais foi de colaboração, ocorrendo desconfianças e críticas mútuas cuja explicação pode estar associada, em parte, a este aspecto, a como é significada a presença dos movimentos sociais nos problemas ambientais, seus nexos e como são compreendidos os determinantes de tais problemas.

Retomando o que é central para um GDP que atua na interface educação ambiental/movimentos sociais, é preciso admitir que a luta pela educação, enquanto direito social inalienável do ser humano, sempre esteve associada às reivindicações mais clássicas dos movimentos sociais. No entanto, a incorporação da temática ambiental como uma "bandeira de luta" é bem mais recente, e mesmo quando ocorre, isso não significa um envolvimento direto com a educação ambiental.

Essa constatação exige uma densa reflexão que não cabe neste artigo introdutório e que, enquanto estudo histórico, pode atender a certos 
interesses de pesquisa futuramente. Todavia, algumas reflexões podem ser pontuadas de início.

A reorganização da sociedade capitalista, principalmente pós1970, levou à reorganização dos próprios movimentos sociais. Tal reestruturação se dá no contexto de expansão do que é denominado por alguns autores como "terceira fase do capitalismo" (FAUSTO, 2002). Esta se caracteriza pela ruptura com o período da "Grande Indústria", reproduzindo-se com forte ênfase nos processos especulativos financeiros e na utilização das ciências, do conhecimento, da tecnologia e da informação como poderosas forças produtivas, lideradas pelo complexo empresarial-militar, destacadamente o dos Estados Unidos. Assim, o capital, saindo de sua fase de expropriação mais direta, de equivalência forma-conteúdo, potencializa e diversifica processos de acumulação e dominação, ao vincular à necessidade de especialidade técnica decorrente da divisão do trabalho os conhecimentos multidimensionais e o uso da informação em tempo real (ANTUNES, 2005; MÉSZÁROS, 1989, 2006). Nesse escopo, a ação individual e a esfera do consumo no ciclo econômico passam a ser determinantes. Vivemos, portanto, em um momento regido não mais exclusivamente por um princípio mecânico-industrial de organização da produção, mas também por um princípio flexível, com profundos efeitos na subjetividade humana, nas formas de organização e de consumo (PRADO, 2005).

Não casualmente, é nessa época que parte da literatura internacional começa a estabelecer uma classificação que divide os movimentos sociais em: (1) movimentos sociais "puros" (voltados para a cidadania, a emancipação, a política e a tomada do Estado, visando a construção de uma outra sociedade); (2) os chamados novos movimentos sociais - NMS (voltados para os valores ditos pós-materialistas, para a libertação pessoal e para a afirmação cultural, com forte ênfase nas subjetividades e nas diferenças).

Em termos históricos, essa alteração societária, que foi acompanhada pelo aguçamento dos processos produtivos destrutivos, se dá, não casualmente, no momento de consolidação do movimento ambientalista (LOUREIRO, 2006b). Este, por sua origem, é identificado, de forma mais imediata, com as forças sociais que se configuram nessa fase 
de reorganização e de profundo questionamento aos padrões de desenvolvimento e ao estilo de vida eurocêntrico dominante. Tal cenário propicia, portanto, que os chamados NMS assumam o "ambiental" de início, como algo inerente às suas finalidades, enquanto os MS, diante de suas históricas lutas políticas e sociais, o fizeram posteriormente e diante das contradições do capitalismo em seu processo de mundialização pautado na intensificação da exploração da força de trabalho e na destruição da base natural. Afinal, como bem coloca Mészáros (2002), essa formação social baseia-se na produção intensa para fins de acumulação da riqueza socialmente produzida, tornando indissociável a violência social da violência ambiental. Ou seja, foram as condições objetivas que propiciaram que o "ambiental" fosse incorporado pelos MS como elemento central nas lutas populares e democráticas e como um componente estratégico para a explicitação dos conflitos socioambientais subjacentes às relações sociais sob o domínio do capital.

O distanciamento dos MS da questão ambiental, quando esta é entendida e configurada apenas no âmbito das discussões sobre a diversidade cultural, a ética e a estética e/ou das relações ecológicas, foi evidente no caso brasileiro. Isso tem várias explicações que merecem igualmente um tratamento de pesquisa posterior. Destacaríamos apenas algumas que facilitam a condução da argumentação elaborada para este texto.

Uma primeira se refere ao próprio modo como o ambientalismo se constituiu, nem sempre próximo das lutas sociais e da ação política emancipatória, gerando dificuldades de diálogo. Um perfil majoritariamente fundado sobre um discurso típico da classe média européia e de abordagens estruturadas na cisão cultura-natureza era e é, evidentemente, incompatível com uma visão socioambiental e igualitária. Outro elemento se relaciona à especificidade brasileira, uma vez que não só os movimentos sociais populares se rearticulam tardiamente (nos anos de 1980), como suas formas de organização se voltaram com muito destaque - não sem motivos e justificativa plausível - para a luta contra a ditadura. Assim, a ênfase se localizava no enfrentamento aos intensos mecanismos de exploração do trabalho e à brutalidade da desigualdade social e no fortalecimento da democracia no país (FONTES, 2006). 
Para quem adota uma perspectiva biologicamente ou tecnologicamente reducionista ou dicotômica entre sociedade e natureza, essas lutas podem parecer irrelevantes para a garantia da proteção ambiental e da conservação ecológica. Contudo, para os que adotam a perspectiva da totalidade natural e da práxis humana, admite-se que, mesmo não sendo "bandeiras" imediatamente cabíveis ao debate ambiental, são, indiscutivelmente, decisivas para a construção de sociedades sustentáveis que garantam a preservação da diversidade cultural e biológica.

Esses dois tipos de "visão de mundo" presentes na leitura de tais processos merecem estudos específicos, tornando-se questões de pesquisa também.

Além desse aspecto pontuado, o complexo cenário em que se movem os agentes sociais está longe de consensos e repleto de polêmicas. Uma delas, por exemplo, refere-se à crescente reflexão sobre o caráter inovador ou não dos NMS. Para não poucos autores, os NMS, quando descolam a luta pela afirmação da diferença e do plural das demais questões, esvaziam o debate político e favorecem a ação fragmentada e focada na esfera do consumo e do indivíduo, reforçando a lógica do efêmero e do imediato (e do liberalismo, em última instância). Assim, mesmo aparentemente se evidenciando como algo novo e libertário, ao se analisar a dinâmica e contradições sociais concretas, verifica-se que não raramente tais movimentos acabam por reproduzir os elementos fundamentais para a reprodução do atual estágio do capitalismo - o efêmero, o imediato, o pragmático, o individual, a análise anistórica (HARVEY, 1992, 2004, 2005).

Sem desconsiderar esse aspecto, para uma boa parte dos pesquisadores sobre o tema, em termos de "pauta de discussão", não há nada de substantivamente novo que configure obrigatoriamente uma polarização entre MS e NMS se estes não se estruturam em cima de reducionismos e mecanicismos que não dão conta da dinâmica societária. Tais autores entendem que o que há de fato de inovador na ação dos agentes sociais contemporâneos é um prolongamento dos MS (o que eliminaria a necessidade do "novo"), uma complexificação da luta política, procurando-se promover simultaneamente os valores igualdade e diversidade e não apenas um destes como se fossem coisas inconciliáveis, 
contemplando as dimensões econômica, política, institucional e cultural (HOUTART, 2006; SANTOS, 2005).

Isso é fundamental de ser anunciado e objetivamente consolidado, pois significa que o tão propagado sentido transformador (ou mesmo revolucionário) do movimento ecológico/ambientalista, neste arranjo contemporâneo, ganha potencialidade ao não mais separar a luta de classe das lutas cotidianas, a afirmação cultural da necessidade de reestruturação econômica, a produção do consumo. Em síntese, representa a aceitação da indissociabilidade constitutiva entre o social e o ecológico.

E, diante desse complexo social, surge uma outra questão de pesquisa: como anda a formação ambiental dos sujeitos que atuam em movimentos sociais (pensados em seu sentido mais amplo)? O "ambiental" é uma temática ou conteúdo explícito dos processos formativos? É um componente estruturante do mesmo?

É possível afirmar que o ambiental, em alguma medida, sempre esteve presente nos processos formativos (formais ou não) quando o foco se encontra nos processos materiais de produção da existência e nos conflitos instaurados diante dos mecanismos de reprodução da economia de mercado (essencialmente produtora de mercadorias), posto que aí se instala objetivamente os modos de apropriação da natureza e a relação metabólica sociedade-natureza. Entretanto, é igualmente verdadeiro afirmar que sua não-centralidade para os movimentos sociais, enquanto categoria de análise e mobilização política, gerou alternativas desenvolvimentistas e que ignoram as condições objetivas dos ecossistemas. É preciso avançar nesse aspecto. Há experiências em andamento em movimentos sociais importantes como MST, Via Campesina, MAB, MTST etc. e em sindicatos da CUT e CGT, mas são modestas diante da necessidade (é preciso uma pesquisa mais apurada sobre isso também).

Após abordar resumidamente esses pontos, há um último, além da discussão estritamente metodológica, não menos polêmico, que precisa ser comentado e amplamente debatido pelo GDP e que se constitui em uma das mais importantes questões de pesquisa diante da situação sociopolítica contemporânea: como as ONGs se inserem aí e atuam como promotoras da EA? 
Para responder à pergunta é preciso lembrar que essas organizações se configuram em um contexto de intensos debates acerca dos conceitos de sociedade civil e de terceiro setor (não casualmente, o mesmo momento histórico da controvérsia sobre MS e NMS). Mais precisamente, no âmbito do deslocamento do entendimento de sociedade civil como terreno das relações sociais de produção material vinculadas à produção de vontades e da consciência, permeadas pela ação do Estado (o que implica conceitos como conflito, militância política, interesses de classe e grupos, hegemonia, ideologia etc.); para um determinado entendimento de terceiro setor que dissocia Estado, mercado e sociedade civil, enfatizando a comunicação, a cooperação, o consenso e o voluntariado, com conotações de rejeição absoluta ao Estado (pensado como instância necessariamente opressora).

Assim, apesar de seu caráter inicial de assessoria a movimentos sociais (sem se confundir com os mesmos, ainda que atualmente ambientalistas erroneamente considerem como sinônimo), as ONGs passam a assumir e legitimar a execução de projetos por entidades da sociedade civil como forma de sobrevivência institucional e relacionamento com governos e empresas, em busca do consenso em relações pretensamente de parceria. São, com isso, amplamente afirmadas como as formas por excelência de organização na atualidade. Contudo, sua ação, quando focalizada na prestação de serviços, esvaziando o debate político, e no voluntariado, secundarizando a militância, tem implicações profundas em termos de democratização do Estado, universalização de políticas públicas e de construção de possibilidades societárias distintas do capitalismo. Algo que reflete no grau de autonomia das mesmas e na capacidade de formulação e intervenção política, ocasionando não raras confusões teóricas, diluição dos efeitos transformadores das práticas efetivadas e "ruídos" no diálogo com os movimentos sociais.

Aqui, portanto, cabem mais algumas questões de pesquisa: como as ONGs contribuem ou não com os movimentos sociais ao agirem por projetos e promoverem a parceria com governos e empresas? Em que medida tal prática afeta a autonomia das mesmas e dos MS? Quais são as motivações que levam à constituição de uma ONG para atuar com EA? 
E, considerando o que foi dito, fica uma pergunta de caráter mais conjuntural: como podemos avaliar a atuação dos movimentos sociais e das ONGs na definição de políticas públicas, sob premissas sustentáveis, no governo Lula, e quais são seus efeitos sobre a consolidação da política de educação ambiental?

\section{Educação ambiental e movimentos sociais: opções metodológicas possíveis}

Por fim, destacamos um aspecto que foi apresentado no GDP e que merece discussões específicas. Quais são as modalidades de pesquisa que se inserem melhor no tratamento dessa relação entre movimentos sociais e educação ambiental?

A priori, não há nenhuma limitação quando se pensa os movimentos sociais como objeto de estudo. Todas as modalidades podem colocar problemas de pesquisa pertinentes que podem ser adequadamente trabalhados e cujos resultados se definam como conhecimentos cientificamente válidos. No entanto, quando entendemos que os próprios movimentos sociais estruturados exigem certas condições para a realização de pesquisas em seu interior e quando assumimos compromissos políticos com esses, adotando como premissa que portam uma práxis educativa relevante para a educação ambiental, algumas modalidades se destacam, principalmente as que se inserem no campo das pesquisas qualitativas, por sua ênfase no entendimento dos processos sociais, da ação dos agentes e das condições históricas que configuram instituições e relações de poder na sociedade.

Contudo, mesmo aí, nem todas são compatíveis. Os posicionamentos funcionalistas e estrutural-funcionalistas, marcadamente organizados sobre premissas positivistas e no pressuposto de que o estudo da sociedade visa sua manutenção e a melhoria cultural dos grupos sociais, ferem frontalmente as orientações epistêmicas e políticas dos MS. Seguindo a classificação de Triviños (2007), poderíamos dizer que, no escopo das pesquisas qualitativas, há basicamente dois conjuntos de abordagens com boa aceitação entre os movimentos sociais: 
- os enfoques subjetivistas-compreensivistas, que privilegiam as percepções, as representações, a cultura, os significados, a realidade mais imediata e a relevância dada pelos sujeitos aos fenômenos - aí se destacam as escolas fenomenológicas e hermenêuticas;

- os enfoques crítico-participativos, que privilegiam o conhecimento das instituições sociais, dos conflitos e processos sociais instaurados pelos sujeitos, e da realidade histórica em suas múltiplas determinações, contradições e complexidade para transformá-la, em um movimento que visa a emancipação humana - aí se destacam as escolas crítico-dialéticas.

Historicamente, até por sua finalidade explícita, por suas implicações políticas e pela inserção histórica de seus principais intelectuais nos movimentos sociais, o segundo conjunto é o que apresenta maior aceitação e maior acúmulo teórico-prático obtido por militantes e pesquisadores que organicamente se vinculam a esses movimentos, o que não representa, contudo, um sentido de exclusividade.

\section{Referências}

ACSELRAD, Henri. Conflitos ambientais no Brasil. Rio de Janeiro: Relume Dumará, 2004.

ACSELRAD, Henri; HERCUlANO, Selene; PÁDUA, José Augusto (Org.). Justiça ambiental e cidadania. Rio de Janeiro: Relume Dumará, 2004.

ANTUNES, Ricardo. Os sentidos do trabalho: ensaio sobre a afirmação e negação do trabalho. 7a reimpressão. São Paulo: Boitempo, 2005.

CALDART, Roseli Salete. Pedagogia do movimento sem terra. São Paulo: Expressão Popular, 2005.

Educação em movimento. Petrópolis: Vozes, 1997.

FAUSTO, Ruy. Marx: lógica e política - investigações para uma reconstituição do sentido da dialética. São Paulo: Editora 34, 2002. Tomo III.

FONTES, Virgínia. Sociedade civil no Brasil contemporâneo: lutas sociais e luta teórica na década de 1980. In: LIMA, Júlio César França; NEVES, Lúcia Maria W. (Org.). Fundamentos da educação escolar do Brasil contemporâneo. Rio de Janeiro: Editora da Fiocruz, 2006. p. 201 240 . 
FREIRE, Paulo. Pedagogia do Oprimido. 18 ed. Rio de Janeiro: Paz e Terra, 1988.

GOHN, Maria da Glória. Movimentos sociais e a construção da cidadania. Educação Pública, Cuiabá, v. 11, n. 19, p. 147-162 jan./jun. 2002.

HARVEY, David. Espaços de esperança. Trad. de Adail Ubirajara Sobral e Maria Stela Gonçalves. São Paulo: Loyola, 2005.

O novo imperialismo. Trad. de Adail Ubirajara Sobral e Maria Stela Gonçalves. São Paulo: Loyola, 2004.

A condição pós-moderna. Trad. de Adail Ubirajara Sobral e Maria Stela Gonçalves. São Paulo: Loyola, 1992.

HOUTART, François. Los movimientos sociales y la construcción de un nuevo sujeto histórico. In: BORON, Atilio; AMADEO, Javier; GONZÁLEZ, Sabrina (Org.). La teoría marxista hoy: problemas y perspectivas. Buenos Aires: CLACSO, 2006. p. 435-444.

LAYRARGUES, Philippe Pomier (Org.). Identidades da educação ambiental brasileira. Brasília: DEA/MMA, 2004.

LIMA, Gustavo Ferreira da Costa. Crise ambiental, educação e cidadania: os desafios da sustentabilidade emancipatória. In: LOUREIRO, Carlos Frederico B.; LAYRARGUES, Philippe Pomier; CASTRO, Ronaldo Souza de (Org.). Educaşão ambiental: repensando o espaço da cidadania. São Paulo: Cortez, 2002. p. 109-142.

LOUREIRO, Carlos Frederico B. Emancipação. In: FERRARO JÚNIOR, Luiz Antonio (Org.). Encontros e caminhos: formação de educadoras(es) ambientais e coletivos educadores. Brasília: MMA, 2007. v. 2, p.157-170.

Crítica ao fetichismo da individualidade e aos dualismos na educação ambiental. Educar em Revista, Curitiba, n. 27, p. 37-54. jan./jun. 2006 .

O movimento ambientalista e o pensamento crítico: uma abordagem política. $2^{\mathrm{a}}$ edição. Rio de Janeiro: Quartet, 2006b.

Trajetória e fundamentos da educaşão ambiental. São Paulo: Cortez, 2004.

MÉSZÁROS, István. A teoria da alienação em Marx. Trad. de Isa Tavares. São Paulo: Boitempo, 2006.

Para além do capital. Trad. de Sérgio Lessa e Paulo Castanheira. São Paulo: Boitempo, 2002. 1989.

Produção destrutiva e Estado capitalista. Trad. de Georg Toscheff. São Paulo: Ensaio,

MONTAÑO, Carlos. Terceiro setor e questão social: crítica ao padrão emergente de intervenção social. São Paulo: Cortez, 2005.

NETTO, José Paulo; BRAZ, Marcelo. Economia politica: uma introdução crítica. São Paulo: Cortez, 2007.

PRADO, Eleutério F. S. Uma nova fase do capitalismo ou um novo modo de produção capitalista? Revista Outubro, São Paulo, n. 13, p. 47-58. 2 sem. 2005.

QUINTAS, José Silva (Org.). Pensando e praticando a educaşão ambiental na gestão do meio ambiente. Brasília: Edições Ibama, 2000. 
SANTOS, Boaventura de Sousa. Os novos movimentos sociais. In: LEHER, Roberto; SETÚBAL, Mariana (Org.). Pensamento crítico e movimentos sociais: diálogos para uma nova práxis. São Paulo: Cortez, 2005. p. 174-189.

SAVIANI, Dermeval. Perspectiva marxiana do problema subjetividade-intersubjetividade. In: DUARTE, Newton (Org.). Crítica ao fetichismo da individualidade. São Paulo: Autores Associados, 2004. p. 21-52.

Pedagogia histórico-crítica: primeiras aproximações. 8a edição. Campinas: Autores Associados, 2003.

SEMERARO, Giovanni. Gramsci e a sociedade civil. Petrópolis: Vozes, 1999.

TERTULIAN, Nicolas. Marx: uma filosofia da subjetividade. Revista Outubro, São Paulo, n. 10, p. 7-16, jan./jun. 2004.

TOZONI-REIS, Marília Freitas de Campos. Educaşão ambiental: natureza, razão e história. Campinas: Autores Associados, 2004.

TRIVIÑOS, Augusto Nibaldo Silva. Introdução à pesquisa em ciências sociais: a pesquisa qualitativa em educação. $15^{\mathrm{a}}$ reimpressão da $1^{\mathrm{a}}$ edição. São Paulo: Atlas, 2007.

Artigo recebido em 11/09/2007 - Aprovado em 02/06/2008 
